\section{Ingested foreign bodies: a new use of endoscopic clips for retrieval}
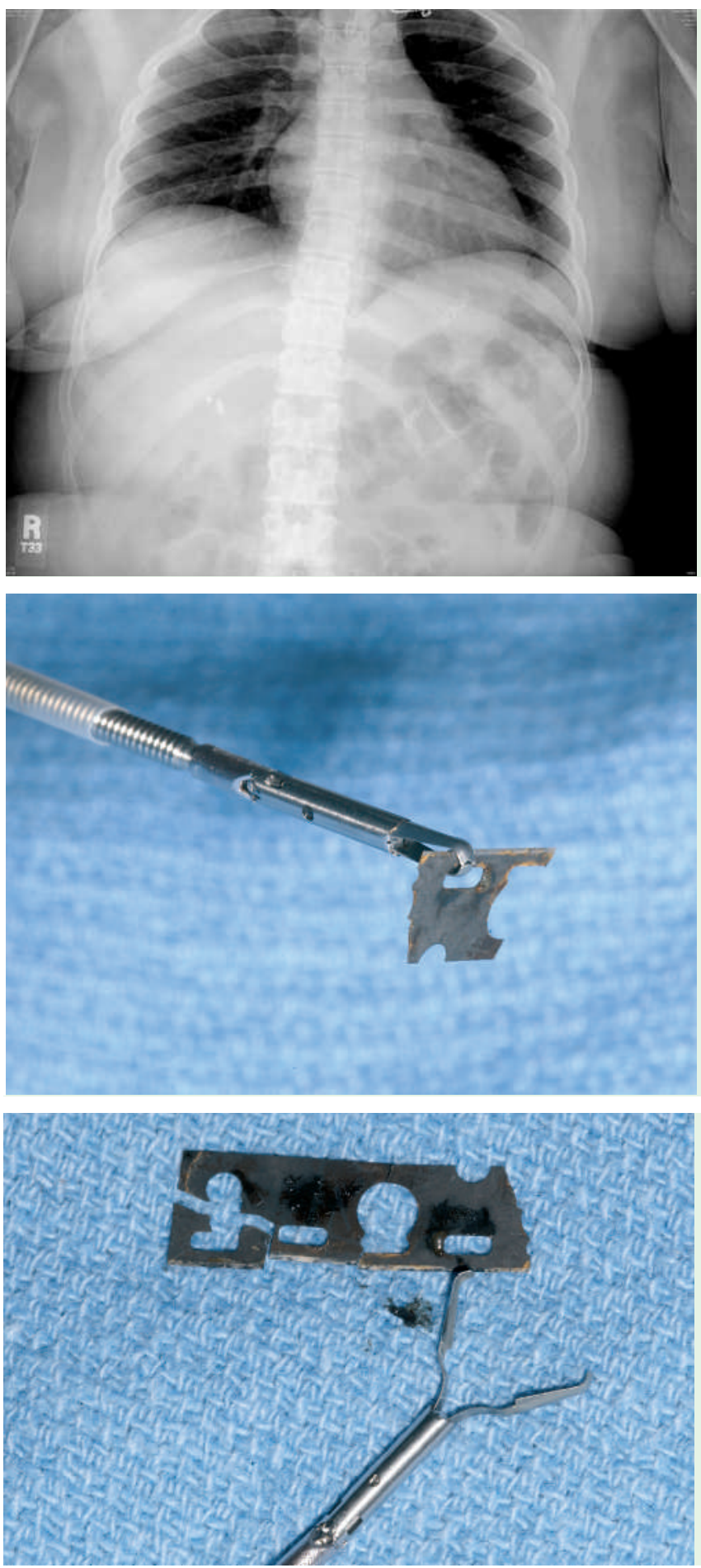

Figure 1 Abdominal radiograph on admission demonstrating three razor blades in the left upper quadrant.

Figure 2 Photographic representation of an endoscopic clip grasping a fragment of the razor blade, simulating the retrieval technique.

Figure 3 Photographic representation of the endoscopic clip in relationship to the retrieved fragments of the razor blade.
Sharp or pointed foreign body ingestions require intervention to prevent perforation and unpredictable migration [1-3]. We report a case of ingested razor blades and a novel use of endoscopic clips for retrieval.

A 24-year-old woman was transferred to our emergency department after ingesting three razor blades. She denied abdominal pain and her abdominal examination was unremarkable. A radiograph revealed three metallic objects, and staples consistent with a cholecystectomy $(\bullet$ Figure 1).

Endoscopy with conscious sedation revealed one razor blade in the fundus. An overtube, rat-tooth grasping forceps, and retrieval net were used to retrieve the blade. However, after multiple attempts, the blade was unable to be removed. A follow-up radiograph revealed the largest blade to be in the left upper quadrant. The other two blades were believed to reside in the colon or small intestine. Under general anesthesia, endoscopy revealed one broken razor blade in the stomach. It was initially grasped with the rat-tooth forceps but again they repeatedly slipped off the surface of the blade and it was not retrieved. An endoscopic clip (Resolution Clip, Boston Scientific Corporation, Natick, Massachusetts, USA) was then positioned near the broken pieces of the blade. The clip was opened and repositioned several times until the hole in the blade was clasped and secured. The endoscopic clip was then placed in the closed and locked position and not deployed ( $\bullet$ Figure 2). Once the razor blade was properly aligned with the esophagus, the overtube was positioned, and the endoscope, overtube, clip, and blade were all removed as a system. The remaining pieces were similarly removed ( $\bullet$ Figure $\mathbf{3}$ ). We believe this is the first reported case of using endoscopic clips for foreign body retrieval in the gastrointestinal tract $[4,5]$. We propose the use of endoscopic clips as an innovative therapeutic maneuver for flat surface foreign-body retrieval or other difficult grasping situations.

Endoscopy_UCTN_Code_TTT_1AO_2AL 
J. G. Thornton, H. Kale, D. R. Ferguson Division of Gastroenterology, MetroHealth Medical Center, Cleveland, Ohio, USA

\section{References}

1 Webb WA. Management of foreign bodies of the upper gastrointestinal tract: update. Gastrointest Endosc 1995; 41: 39-51

2 Selivanov V, Sheldon GF, Cello JP, Crass RA. Management of foreign body ingestion. Ann Surg 1984; 199: 187-191

3 Witzel L, Scheurer U, Muhlemann A, Halter F. Removal of razor blades from stomach with fibreoptic endoscope. Br Med J 1974; 2: 539

4 Chuttani R, Barkun A, Carpenter S et al. Endoscopic clip application devices. Gastrointest Endosc 2006; 63: 746 - 750

5 Raju GS, Gajula L. Endoclips for GI endoscopy. Gastrointest Endosc 2004; 59: 267-279
Bibliography

DOI $10.1055 / \mathrm{s}-2007-966553$

Endoscopy 2007; 39: E164-E165

(c) Georg Thieme Verlag KG Stuttgart · New York . ISSN 0013-726X
Corresponding author

\section{J. G. Thornton, MD}

Division of Gastroenterology MetroHealth Medical Center 2500 MetroHealth Drive

Cleveland

$\mathrm{OH} 44109$

USA

Fax: +1-216-778-4873

jthornton@metrohealth.org 